\title{
Throat Carrier Rate of Streptococcus pneumoniae among Students Living in Hostels in a Higher Institution
}

\author{
B.O. Oluboyo ${ }^{1} *$ and A.O. Oluboyo ${ }^{2}$ \\ ${ }^{1}$ Department of Medical Laboratory Science, College of Medicine and \\ Health Sciences, Afe Babalola University, Nigeria \\ ${ }^{2}$ Department of Medical Laboratory Science, College of Medicine and Health Sciences, \\ Afe Babalola University, Ado Ekiti, Nigeria \\ *Corresponding author
}

\section{Keywords \\ Throat Carrier, Streptococcus pneumoniae, Moraxella catarrhalis. \\ Article Info \\ Accepted: 19 June 2017 Available Online: 10 July 2017}

\section{A B S T R A C T}

Streptococcus pneumoniae has been found responsible for a number of diseases in man. It lives harmlessly in the human throat where, if opportune, can cause diseases in the host or be transmitted to other susceptible persons through coughing and sneezing. This study investigated the carrier rate of the organism among students living in hostels in a higher institution. A total of 168 samples were collected from the students whose ages range between 20 and 40 and comprising of 84 males and 84 females. The samples were cultured on blood and chocolate agar. Isolates were identified using standard procedures and tested for antibiotic sensitivity using disc diffusion method. A total of 22 Streptococcus pneumoniae were isolated from the samples giving a carrier rate of $13.1 \%$. Throat carriage of Moraxella catarrhalis, viridians Streptococci, non-haemolytic Streptococci, albus Staphylococci and some Gram negative bacilli were recorded as $85.7 \%, 51.2 \%, 26.8 \%$, $3.6 \%$ and $2.4 \%$ respectively. Carrier rate was found to decrease with increase in age. A rate of $14.3 \%$ was seen in females as against $11.9 \%$ in males. There was no significant ( $>0.05)$ increase in the throat carriage of the organism in female in relation to the males. Streptococcus pneumoniae rate of coexistence with non-haemolytic streptococcus was recorded as $31.8 \%$ while coexistence rate with Moraxella catarrhalis was $72.7 \%$. The organism did not coexist with viridians streptococci, albus staphylococci and the Gram negative bacteria isolated. Streptococcus pneumoniae recorded $100 \%$ sensitivity against ceftriazone, ceftaxidime, cefuroxime, erythromycin and ampicillin; $82 \%$ against cotrimoxazole and $68 \%$ against tetracycline.

\section{Introduction}

Streptococcus pneumoniae (pneumococci) are carried harmlessly in the throat of many persons (Ross, 2014). When a parasite comes in contact with a normal host surface, its establishment is first countered by the defense mechanisms of the host. These include the skin and the mucous membranes which form protective surface barriers. Each surface has some means of getting rid of microorganisms, with the result that only specially adapted types of microorganisms can survive on it (Willey et al., 2011). Some factors that enable pneumococci to overcome the immune response of the host and eventually account for its invasiveness include the capsule, $\operatorname{Ig}$ A protease, pneumolysin and autotysin (Kilian, 
2012). Streptococcus pneumoniae generally remains harmless in the carrier unless it is provoked by a viral infection such as influenza to spread to the lower respiratory tract, middle ear, paranasal sinus or the blood (Ross, 2014). Throat carrier rate of pneumococcus is said to range $0 \%$ and $70 \%$ (Ross, 2014; Kilian, 2012). Willet (1984) recorded carrier rates of pneumococci in children as $25-50 \%$. With increase in age the rate is said to become lowered to $18 \%$ in adult and may be only $5 \%$ in adults having no contact with children (Willet, 1984). In military installations, where the incidences of pneumococcal infections are high, carrier rates may be as high as $60 \%$ (Willet, 1984). The transmission rate of Streptococcus pneumoniae is directly influenced by the carrier rate in a given population (RegevYochay et al., 2004). Pneumococcal infection may readily spread to susceptible individuals living in overcrowded accommodation such as found in resource limited settings and some school hostels and military installations. Carriers of microorganisms play an important role in the epidemiology of diseases associated with such organisms (Willey et al., 2011). Behavioral factors contributing to the increasing burden of respiratory disease in Nigeria include the increasing prevalence of cigarette smoking and alcoholism (Kilian, 2012). Other common predisposing factors include respiratory viral infections, advancing age, little children and immune deficiency especially HIV/AIDS (Kilian, 2012).

The incidence of pneumococcal disease is highest in children $<2$ years of age and in adults $>65$ years of age (Ortavist et al., 2005). Streptococcus pneumoniae was responsible for $8.8 \%$ cases of otitis media among children in Ile-Ife (Ako-Nai, 2002), $4.6 \%$ conjunctivitis among children in Ibadan (Adeyeba et al., 2010), 7.5\% cases of bacterial infections in children in Abuja (Onalo et al., 2011). In South Africa, 74.5\% (35 children out of 47) children with otitis media were due to Streptococcus pneumoniae (Huebner et al., 2003). Several studies have examined household transmission of Streptococcus pneumoniae; most of such studies have suggested that children were the source of transmission to adults in the family (Hoshino et al., 2002; Shimada et al., 2002, Leino et al., 2001). Oniyangi et al., (2006) reported that $60 \%$ of HIV/AIDS patient children in Abuja were admitted based on the diagnosis of pneumonia and this disease caused the death of $71.4 \%$ of them. Moreover, in Ilorin, Adejuyigbe et al., (2003) found that 46.3\% death in HIV infected children was due to pneumonia. None of these studies investigated the aetiology of pneumonia in these children, which is an important area of study for preventive interventions. Neither a comprehensive study on the prevalence of Streptococcus pneumoniae nor the carrier rate of the organism among students living in hotels is readily available. This study aim at evaluating the throat carrier rate of Streptococcus pneumoniae among students undergoing training in Obafemi Awolowo University Teaching Hospital Complex and living in the school hostel.

\section{Materials and Methods}

\section{Study area}

This study was done in the Microbiology Laboratory of Obafemi Awolowo University Teaching Hospital Complex (OAUTHC), IleIfe. The built-up area of Ile-Ife is about $88 \mathrm{Km}^{2}$ and has population of 501,952 (Ajala and Olayiwola, 2013). It is located between latitudes $7^{\circ} 28^{\prime} \mathrm{N}$ and $7^{\circ} 45^{\prime} \mathrm{N}$ and longitudes $4^{\circ} 30^{\prime} \mathrm{E}$ and $4^{\circ} 34^{\prime} \mathrm{E}$ (Ajala and Olayiwola, 2013).

\section{Study design}

This is a cross sectional study involving random sampling of students living in the school hostels. 


\section{Sample size}

A total of 168 students living in the hostels were sampled for this study. This number consisted of 84 males and 84 females all within ages 20 to 40 years.

\section{Specimen collection and processing}

Sterile swab sticks were used to swab the throats of apparently normal subjects and taken to the laboratory for examination with a maximum delay of 30 minutes. The samples were streaked directly on freshly prepared sterile heated 5\% sheep blood agar (chocolate agar) and 5\% sheep blood agar plates. The chocolate plates were incubated in an atmosphere of 5-10\% carbondioxide (in $\mathrm{CO}_{2}$ Jar) at $37^{\circ} \mathrm{C}$ for 24 hours (Ross, 2014). The blood agar plates were incubated at same temperature and 24 hours.

\section{Identification of Streptococcus pneumoniae}

Streptococcus pneumoniae was identified based on colonial appearance, Gram stain, catalase test, bile solubility and optochin sensitivity. Colonies that are Gram positive diplococci, showing greenish coloration on chocolate agar and partial-haemolysis on blood agar, with 'draughtsman'colonies, catalase negative, bile soluble and optochin sensitive were identified as Streptococcus pneumoniae (Ross, 2014; Murray et al., 2003). Viridans Streptococci were differentiated from Streptococcus pneumoniae through appearance of entire edges, Gram positive cocci in chains, greenish coloration on blood agar, resistance to optochin and insolubility in $10 \%$ bile salts (UK Standards for Microbiology Investigations, [SMIs], 2014). Other non-haemolytic viridians Streptococci were identified as having no colour change or clearing of the medium (SMIs, 2014). Gram positive cocci in clusters, catalase positive and coagulase negative were recorded as albus staphylococci. Moraxella catarrhalis was distinguished from Streptococci by Gram reaction (Gram negative) and oxidase test (positive).

\section{Preparation of Streptococcus pneumoniae inoculum}

The direct colony suspension method [Clinical and Laboratory Standards Institute (CLSI), 2014] was used. Colonies were taken from an overnight 5\% sheep blood agar plate and emulsified in $5 \mathrm{ml}$ of Mueller-Hinton broth and compared with 0.5 McFarland standard, adjusting the turbidity by diluting with sterile distilled water or by adding more colonies. The inoculum was used to inoculate sensitivity plate within 15 minutes.

\section{Antibiotic susceptibility testing}

Commercially prepared antibiotic discs of $30 \mu \mathrm{g}$ ceftriaxone, $30 \mu \mathrm{g}$ ceftaxidime, $30 \mu \mathrm{g}$ cefuroxime, $30 \mu \mathrm{g}$ erythromycin $25 \mu \mathrm{g}$ cotrimoxazole, $30 \mu \mathrm{g}$ ampicillin, and $30 \mu \mathrm{g}$ tetracycline were tested against Streptococcus pneumoniae on Mueller-Hinton agar. The disc diffusion method (Mounyr et al., 2016; CLSI, 2012) was used for testing the sensitivity of Streptococcus pneumoniae against commercially prepared antibiotic discs. Mueller-Hinton agar incorporated with 5\% sheep blood was used. A loopful of the inoculums was applied to the Mueller-Hinton agar and spread evenly using sterile swab. The tests were incubated at $37^{\circ} \mathrm{C}$ for 24 hours in an atmosphere of $10 \% \quad \mathrm{CO}_{2}$. The sensitivity was determined according to CLSI (2012) recommendation.

\section{Statistical analysis}

The data generated were analyzed using statistical package for Social Science version 17. The probability level was set at 0.05 . 


\section{Results and Discussion}

The comparative carrier rates of Streptococcus pneumoniae in relation to other bacteria isolates from the throats of 168 participants are represented in table 1. The carrier rate of Streptococcus pneumoniae recorded was $13.1 \%$. Moraxella catarrhalis recorded the highest carrier rate of $85.7 \%$ followed by viridians Streptococci, nonhaemolytic Streptococci, Streptococcus pneumoniae, and albus Staphylococci respectively. A few Gram Negative bacilli accounted for $2.4 \%$ throat carriage of bacteria. The rates of coexistence of Streptococcus pneumoniae $(\mathrm{n}=22)$ with other bacteria found in the throat is presented in table 2. Streptococcus pneumoniae was found to have high rate of coexistence with Moraxella catarrhalis $(72.7 \%)$ and $31.8 \%$ rate of coexistence with non-haemolytic Streptococci. The organism was not found to coexist with viridians Streptococci and albus staphylococci. The carrier rates of Streptococcus pneumoniae in relation to age is represented in table 3. The rate of coexistence appears to decrease with age. Throat carriage of the organism in female was $14.3 \%$ while the value recorded for the males was $14.3 \%$. Carrier rate in female is not significantly higher $(p>0.05)$ than males. The antibiotic sensitivity pattern of Streptococcus pneumoniae isolated in the throat of apparently healthy students is shown in table 4. Streptococcus pneumoniae was $100 \%$ sensitive to ceftriaxone, ceftaxidime, cefuroxime, erythromycin and ampicillin. The organism recorded $82 \%$ sensitivity against cotrimoxazole. The lowest sensitivity of 59\% was recorded against tetracycline.

The throat carriage of Streptococcus pneumoniae in this study (13.1\%) falls within the range of $0-70 \%$ as recorded by Ross (2014) and Kilan (2012). The rate is lower than $25-50 \%$ found in children (Willet, 1984) and lowers than $18 \%$ recorded as adult carriage of pneumococcus (Willet, 1984). The throat carriage appeared to be reducing with age. Throat carrier rate was higher $(14.0 \%)$ among students that are 20-25 years old than in students that are 36-40 years old (8.0\%). No record of throat or nasal carriage of the organism in other higher institutions of learning was found in Ile-Ife or elsewhere in Nigeria. The finding of this work is however lower than $60 \%$ recorded in military installations (Willet, 1984). The carrier rate is said to be high in children. These could be the reason why higher (though not statistically significant, $p>0.05$ ) rate was found in female more than males as females generally have contacts with children more than males.

Streptococcus pneumoniae is most likely to be antagonized by viridians Streptococci in the throat as no Streptococcus pneumoniae was found to coexisting with viridians Streptococci in the throat despite the high carrier rate of viridians Streptococci. Production of antimicrobial agent (bacteriocin) by resident viridians Streptococci possibly antagonized Streptococcus pneumoniae in the throat. This might be the explanation for lack of coexistence between pneumococci and viridians Streptococci and some Gram negative bacilli in this study. The normal flora may out-compete other microorganisms for available nutrients, thus starving them and preventing them from multiplying. Some members of the normal flora produce antibacterial chemicals (bacteriocins) as a side product of their metabolism, thus generating a local antibiotic effect which hinders the invader (The Crohnie, htt://primer.crohn.ie/ human-normal-flora). Streptococcal infection has been identified as an important cause of severe disease in Nigeria (Onalo et al., 2011). 
Table.1 Comparative carrier rates of Streptococcus pneumoniae in relation to other bacteria isolated from the throat of the subjects $(n=168)$

\begin{tabular}{ccc}
\hline Organisms & Total Organism Isolated & Carrier Rate (\%) \\
\hline Streptococcus pneumoniae & 22 & 13.1 \\
\hline Moraxella catarrhalis & 144 & 85.7 \\
Viridians Streptococci & 86 & 51.2 \\
Non-haemolytic Streptococci & 45 & 26.8 \\
Albus Staphylococci & 6 & 3.6 \\
Gram negative bacilli & 4 & 2.4 \\
\hline
\end{tabular}

Table.2 The rates of coexistence of Streptococcus pneumoniae $(\mathrm{n}=22)$ with other bacteria found in the throat

\begin{tabular}{ccc}
\hline Organisms & $\begin{array}{c}\text { Number of } \text { S. pneumonae } \\
\text { coexisting with other bacteria }\end{array}$ & Rate of coexistence (\%) \\
\hline Viridians Streptococci & 0 & 0 \\
Non-haemolytic Streptococci & 7 & 31.8 \\
Moraxella catarrhalis & 16 & 72.7 \\
Albus staphylococci & 0 & 0 \\
Gram negative bacilli & 0 & 0 \\
\hline
\end{tabular}

Table.3 Carrier rates of Streptococcus pneumoniae within different ages

\begin{tabular}{cccc}
\hline Age limit & $\begin{array}{c}\text { Number of subjects } \\
\text { sampled }\end{array}$ & $\begin{array}{c}\text { Number of } \boldsymbol{S} \text {. } \\
\text { pneumoniae isolated }\end{array}$ & Carrier rate (\%) \\
\hline $20-25$ & 57 & 8 & 14.0 \\
$26-30$ & 53 & 8 & 15.1 \\
$31-35$ & 33 & 4 & 12.1 \\
$36-40$ & 25 & 2 & 8.0 \\
Total & 168 & 22 & 13.1 \\
\hline
\end{tabular}

Table.4 Antibiotic sensitivity pattern of Streptococcus pneumoniae isolated in the throat of apparently healthy students

\begin{tabular}{cccccc}
\hline & & \multicolumn{4}{c}{ Sensitivity } \\
\cline { 3 - 6 } $\begin{array}{c}\text { Antimicrobial } \\
\text { agents }\end{array}$ & Unit (mcg) & $\mathbf{S}$ & $\mathbf{R}$ & $\begin{array}{c}\text { Percentage } \\
\text { resistance }\end{array}$ & $\begin{array}{c}\text { Percentage } \\
\text { sensitivity }\end{array}$ \\
\hline Ceftriaxone & 30 & 22 & 0 & 0 & 100 \\
Ceftazidime & 30 & 22 & 0 & 0 & 100 \\
Cefuroxime & 30 & 22 & 0 & 0 & 100 \\
Erythromycin & 30 & 22 & 0 & 0 & 100 \\
Cotrimoxazole & 25 & 18 & 4 & 18 & 82 \\
Ampicillin & 30 & 22 & 0 & 0 & 100 \\
Tetracycline & 30 & 15 & 7 & 32 & 68 \\
\hline
\end{tabular}

Record are however scanty on characterization of streptococcal species in bacterial infections in Nigeria (Onalo et al., 2011). In a study of
Streptococcal species identification of bacterial infection in Abuja (Nigeria), the researchers reported that $58.8 \%$ (10 out of 17 isolates of 
Streptococcus typed) of streptococcal infection were caused by Streptococcus pneumoniae (Onalo et al., 2011). Streptococcus pneumoniae has been found to cause a lot of diseases in man, some of which are extremely dangerous. The organism is a frequent cause of such deadly disease as pyogenic meningitis.

In a childhood community-acquired pneumonia study between year 2011 and 2013, Kuti and Oyelami (2015) observed that pneumococcus accounted for $23.5 \%$ of the cause of admission for the total children admitted from one month to 15 years of age in Wesley Guild Hospital, Ilesa, Nigeria. Recent records are not found on characterization of streptococcal infections in Ile-Ife, Nigeria, but in OAUTHC, Ile-Ife, Nigeria, and between 1977 and 1982, 8.0\% out of $14.1 \%$ cases of pneumonia diagnosed was found to be due to Streptococcus pneumoniae (Lasisi, 1983). Carriers of Streptococcus pneumoniae remain a constant source of infection in any given community. A reduction in the number of carriers of a particular organism will go a long way in reducing the incidence of such diseases caused by the organism. This is very significant in view of the fatality rate of this bacterium.

In conclusion, the carrier rate of $13.1 \%$ was recorded among students of Obafemi Awolowo University Teaching Hospital living in the school hostels. A coexistence rate of $31.8 \%$ and $72.7 \%$ were recorded against non-haemolytic Streptococci and Moraxella catarrhalis respectively. None of the pneumococcus was found to coexist with viridians Streptococci, albus Staphylococcus and other Gram negative bacilli in the throat. This study has been able to point out to clinicians, Scientists, epidemiologists and other health professionals the carrier rate of Streptococcus pneumoniae among students living in the hostels in Ile-Ife. If carriers of a particular organism is significant in the transmission of infection to susceptible members of the community, it follows that throat carriage of Streptococcus pneumoniae may need to be considered and controlled especially in settings (such as school hostels and military installations) where people are more likely to spread the organism through inhalation of bacteria in tiny droplets in air.

\section{Acknowledgement}

The cooperation of staff of Medical Microbiology Unit of Obafemi Awolowo University Teaching Hospital in making the work a success is appreciated.

\section{Conflict of interest}

The authors express no conflict of interest in this study.

\section{References}

Adejuyigbe, E.A., O. Oyelami, O, Onayemi and Durosimi, M.A. 2003. Paediatric HIV in Ile-Ife, Nigeria. Cent Afr. J. Med., 49: 7478.

Adeyeba, O.A., M.C. Anorue, O.A. Adefioye, Y.O. Adesiji, A.A. Akindele, O.S. Bolaji and Adewuyi, I.K. 2010. Conjunctivitis among children in a teaching hospital in South-West Nigeria: role of Staphylococcus aureus as an aetiologic agent and its antibiogram. African J. Microbiol. Res., 4(19): 1945-1948.

Ako-Nai, A.K., F.A. Oluga, A.O. Onipede, E. A. Adejuyigbe and Amusa, Y.B. 2002. The characterization of bacterial isolates from acute otitis media in Ile-Ife, southwestern Nigeria. J. Trop. Pediatr., 48(1): 15-23.

Ajala, O.A. and Olayiwola, A.M. 2013. An Assessment of the Growth of Ile-Ife, Osun State Nigeria, Using Multi-Temporal Imageries. J. Geography and Geol., Vol. 5, No. $2 . \quad$ doi: http://dx.doi.org/10.5539/jgg.v5n2p43

Clinical and Laboratory Standards Institute, CLSI. 2012. Performance Standards for antimicrobial disk susceptibility test, Approved Standard, $11^{\text {th }}$ edn, CLSI document M02-All. Wayne, Pennsylvania: Clinical and Laboratory Standards Institute. Hoshino, K., H. Watanabe, R. Sugita, N. Asoh, S.A. Ntabuguzi, K. Watanabe, K. Oishi and Nagatake, T. 2002. High rate of 
transmission of penicillin-resistant Streptococcus pneumoniae between parents and children. J. Clin. Microbiol., 40: 43573459.

Huebner, R.E., A.D. Wasas, M. Hockman. Klugman, K.P., ENT Study Group. 2003. Bacterial aetiology of non-resolving otitis media in South African children. $J$. Laryngol. Otol., 117(3): 169-172.

Kilian, M. 2012. Streptococcus and Enterococcus. In: Greewood, D., Barer, M., Sllack, R., Irving, W. (Eds). Medical Microbiology. $18^{\text {th }}$ Edn. Churchill Livingstone: Edinburgh. Pp 183-198.

Kuti, B.P., and Oyelami, A.O. 2015. Childhood community-acquired pneumonia at the Wesley Guild Hospital, Ilesa: Prevalence, Pattern, and Outcome determinants. Niger. J. Health Sci., 15: 98-104

Lasisi, B.O. 1983. Bronchitis and pneumonia in infant and children: a retrospective study of case admitted to Ife University Teaching Hospital complex between 1977 and 1982, Ile-Ife (Nigeria). Pp 34-35.

Leino, T., K. Auranen, J. Jokinen, M. Leinonen, P. Tervonen and Takala, A. K. 2001. Pneumococcal carriage in children during their first two years: important role of family exposure. Pediatr. Infect. Dis. J., 20: 1022-1027.

Mounyr, B., S. Moulay, and Saad, K.I. 2016. Methods for in vitro evaluating antimicrobial activity: a review. $J$. Pharmaceutical Analysis, 6(2): 71-79.

Murray, P.R., E.J. Baron, J.J. Jorgensen, M.A. Pfaller and Yolken, R.H. 2003. Mannual of Clinical Microbiology, $8^{\text {th }}$ Ed. ASM Press: Woshington BC.

Onalo, R., S.I. Adeleke, C. Nwolorzie, and Njoku, R. 2011. Rate of isolation of Streptococcus species from children with bacterial infection: an indication of streptococcal vaccines. Nigerian J. Paediatrics, 38 (3): 136-141

Oniyangi, O.B. Awani, and Iregbu, K.C. 2006. The pattern of paediatric HIV/AIDS as seen at the national Hospital, Abuja. Niger. J. Clin. Pract., 9: 153-158.

Ortavist, A., J. Hedlund, and Halin, M. 2005. Streptococcus pneumoniae: epidemiology, risk factors, and clinical features. Semin. Respir. Crit. Care Medi., 26(8): 563-574

Regev-Yochay, G., M. Raz, R. Dagan, N. Porat, B. Shainberg, E. Pinco, N. Keller, and Rubinstain, E. 2004. Nasopharyngeal carriage of Streptococcus pneumoniae by adults and children in community and family setting. Clin. Infectious Dis., 38(5): 632-639.

Ross, P.W. 2014. Streptococcus pneumoniae. In: Collee J. G., Fraser A. G., Marmion B. P., Simions A. (Eds), Mackie and McCartney Prectical Microbiology, $14^{\text {th }}$ Edn. Chuchill Livingstone: India. Pp 275-281

Shimada, J., N. Yamanaka, M. Hotomi, N. Suzumoto, A. Sakai, K. Ubukata, T. Mitsuda, Faden, H. 2002. Household transmission of Streptococcus pneumoniae among siblings with otitis media. J. Clin. Microbiol., 40: 1851-1853.

UK Standards for Microbiology Investigations. 2014. Identification of Streptococcus species, Enterococcus species and morphologically similar organisms. Public Health England, 4(3): 1-36.

Willet, H.P. 1984. Streptococcus pneumoniae. In: Joklik, W. K., Willet H. P., Amos, D. B. (Eds), Zinsser Microbiology, $18^{\text {th }}$ ed. Appleton-Century-Croft publication: Connecticut. Pp. 477-488.

Willey, J.M., L.M. Sherwood, Woolverton C.J. 2011. Prescott's Microbiology. $8^{\text {th }}$ Edn, McGraw-Hill: New York. Pp 760-788.

\section{How to cite this article:}

Oluboyo, B.O. and Oluboyo, A.O. 2017. Throat Carrier Rate of Streptococcus pneumoniae among Students Living in Hostels in a Higher Institution. Int.J.Curr.Microbiol.App.Sci. 6(7): 1573-1579. doi: https://doi.org/10.20546/ijcmas.2017.607.189 